\title{
Experiment study on performance of air source heat pump
}

\author{
Weixiu Shi ${ }^{1,}$, , Lisheng Pan $^{2, b}$ \\ ${ }^{1}$ School of Environment and Energy Engineering, Beijing University of Civil Engineering and \\ Architecture, Beijing 100044, China \\ ${ }^{2}$ State Key Laboratory of High-temperature Gas Dynamics, Institute of Mechanics, Chinese \\ Academy of Sciences, Beijing 100190, China \\ ashiweixiu@bucea.edu.cn, b panlisheng@imech.ac.cn
}

Keywords: air source heat pump, exhaust temperature, evaporator outlet temperature, outlet presser of compressor

\begin{abstract}
Under the situation of energy crisis, air source heat pumps are paid more attention recently. In order to save energy, the feasibility and performance of air source heat pump are studied by experiment, and variation laws of exhaust temperature, evaporator outlet temperature and outlet presser of compressor were analyzed in this paper. Air source heat pump apparatus were set up and the experiment was during $10^{\circ} \mathrm{C}, 20^{\circ} \mathrm{C}, 30^{\circ} \mathrm{C}$ and $40^{\circ} \mathrm{C}$. The results were as follows: exhaust temperature of compressor increases gradually with the increase of tank temperature, but the temperature difference between exhaust temperature of compressor and tank temperature becomes little; temperature difference in evaporator decreases; Compressor outlet pressure increases obviously.
\end{abstract}

\section{Introduction}

Air source heat pump water heater has great potential for energy savings comparing to electric heating. At present, many scholars have carried out research on the performance of air-source heat pump and optimization. Weiguo Li etal[1] studied performance by using electronic expansion valve for air-source heat pump, and created a dynamic numerical model. The results showed that switching expansion valve opening degree can improve system performance. Jibo Hao etal[2] investigated influencing factors of flow and refrigerant rate, it was found that heat capacity and COP increase with the rise of environmental temperature, and the heat capacity increased with increase of air flow rate at the beginning. Ruzhu Wang, Jingyi Wu etal [3-6] studied performance of air source heat pump by factors of length of condensor coil, expansion valve opening, set temperature of tank, filling ratio of refrigerant and tank volume.

\section{Experimental Apparatus and Procedure}

The experiment system is shown in Figure 1. The air source heat pump consist of water tank of $120 \mathrm{~L}$ and other accessories. The experiment system was set in a constant temperature room, so as to simulate and adjust the environment temperature and humidity, which are controlled by large scale heat pump unit. The temperature measure points are shown with a legend $\mathrm{T}$, and the pressure measure points are with a legend $\mathrm{P}$. In order to reduce heat loss, the outer surface of water tank is insulated by polyurethane with thickness of $25 \mathrm{~mm}$. The temperatures were measured by thermo-couples which had been verified by a standard quartz thermometer with a precision of $0.05^{\circ} \mathrm{C}$. The temperature variations were automatically monitored by a data acquisition unit (HP-34970A). The pressure is also measured by vacuum manometer with high accuracy, and the power is monitored by wattmeter. There are four temperature measure points in the condensed tank, and the average value of the four is used as calculated temperature. Medium-high temperature refrigerant of ZHR02 was used during the experiment. 


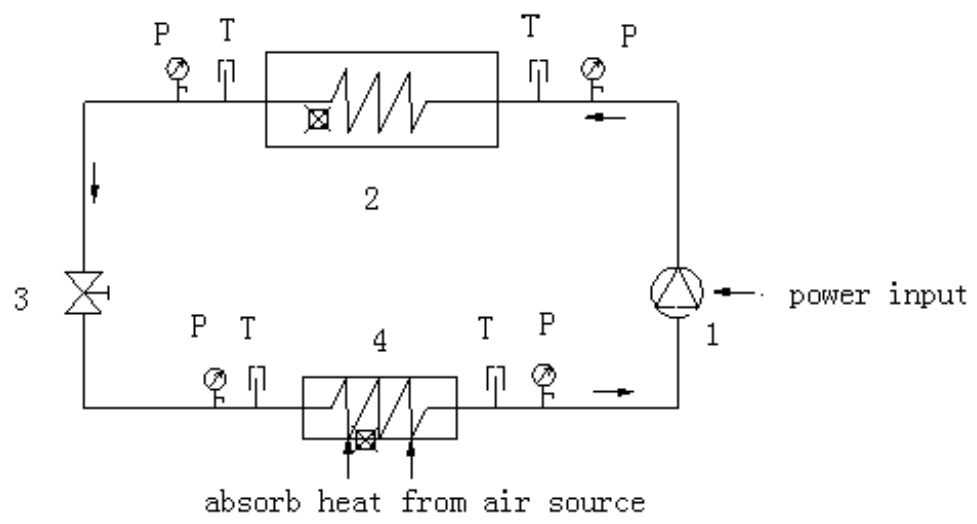

1-compressor; 2-condenser; 3-throttling element; 4-evaporator

Fig.1 Experimental apparatus of air source heat pump

Capillary of $0.8 \mathrm{~m}$ was chosen as the throttling element in the experiment. Data were collected per $10 \mathrm{~min}$. Variation laws of exhaust temperature, evaporator outlet temperature and outlet presser of compressor were analyzed in the paper.

\section{Experimental Results and Discussions}

The initial temperature of water inside the tank is $35^{\circ} \mathrm{C}$, and ambient temperature was adjusted to $10{ }^{\circ} \mathrm{C}, 20{ }^{\circ} \mathrm{C}, 30{ }^{\circ} \mathrm{C}$ and $40{ }^{\circ} \mathrm{C}$. Variation laws of exhaust temperature and water temperature with time as shown in Figure 2-5.

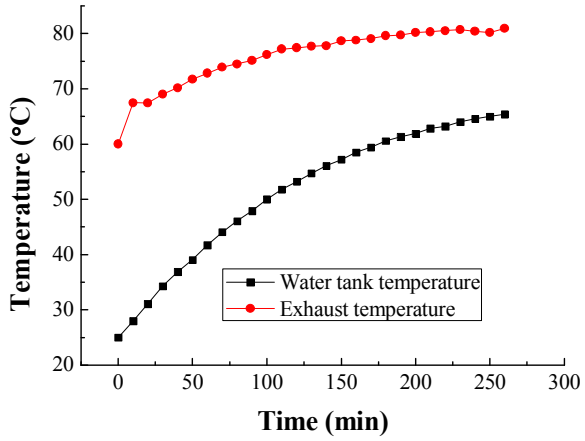

Fig. $210^{\circ} \mathrm{C}$

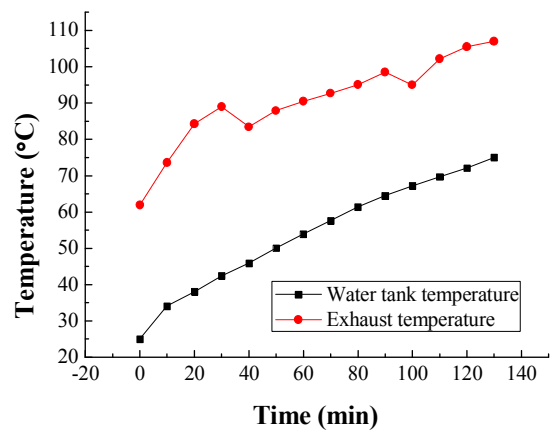

Fig. $30^{\circ} \mathrm{C}$

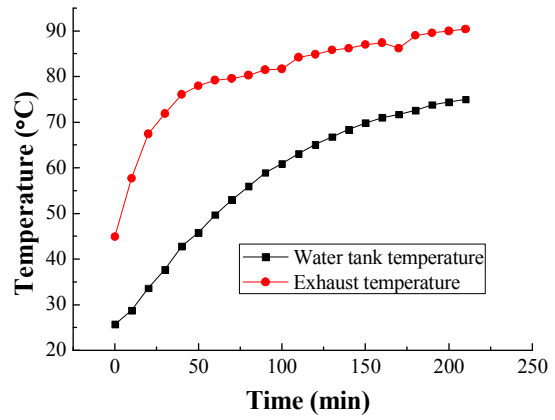

Fig. $320^{\circ} \mathrm{C}$

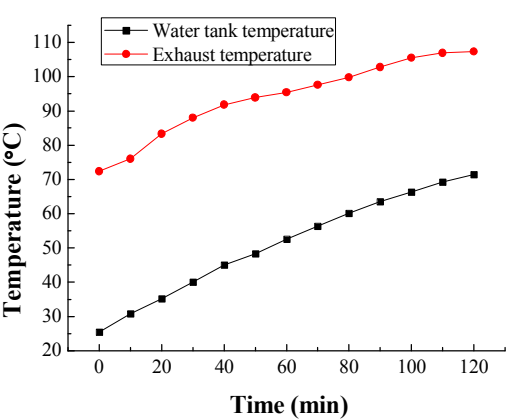

Fig. $540^{\circ} \mathrm{C}$

As shown in Fig. 2-5, exhaust temperature of compressor increases gradually with the increase of tank temperature, but the temperature difference between exhaust temperature of compressor and tank temperature becomes little. Therefore, heat transfer performance becomes bad and heat transfer quantity decreases with the increase of tank temperature. As shown in Fig. 4 and Fig. 5, exhaust temperature increases rapidly with the increase of tank temperature. Because tank temperature is much high, condensing temperature is also much high. The highest exhaust temperature is higher than 
$100^{\circ} \mathrm{C}$ and is close to the limit exhaust temperature which is not higher than $125^{\circ} \mathrm{C}$. When surrounding temperature is $10^{\circ} \mathrm{C}$ and $20^{\circ} \mathrm{C}$, heat pump system can only run with low evaporating temperature and condensing temperature. Then exhaust temperature of compressor is also low.

On the case of ambient temperature of $10^{\circ} \mathrm{C}, 20^{\circ} \mathrm{C}, 30^{\circ} \mathrm{C}, 40^{\circ} \mathrm{C}$, evaporator outlet air temperature changes over time as shown in Figure 6-9.

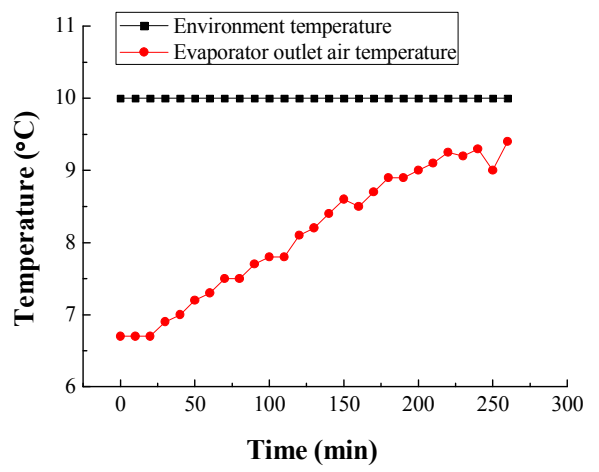

Fig.6 $10^{\circ} \mathrm{C}$

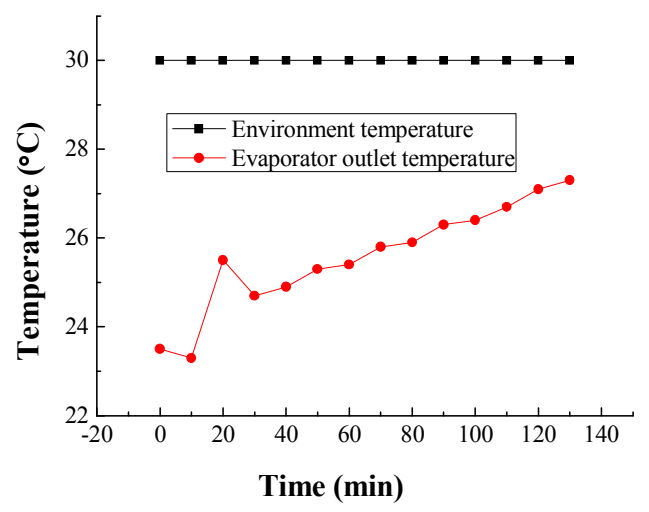

Fig. $80^{\circ} \mathrm{C}$

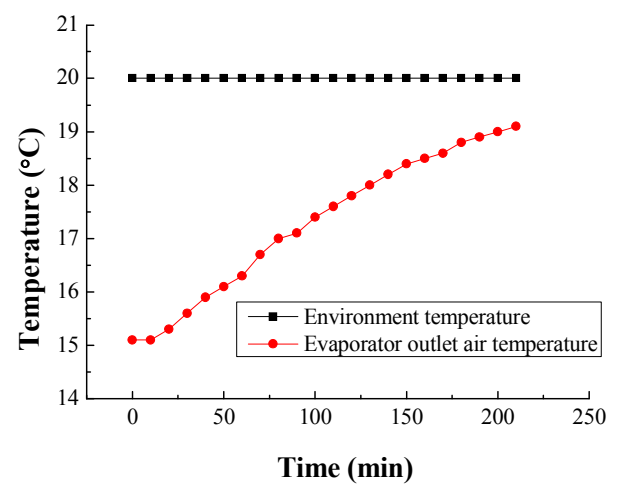

Fig. $720^{\circ} \mathrm{C}$

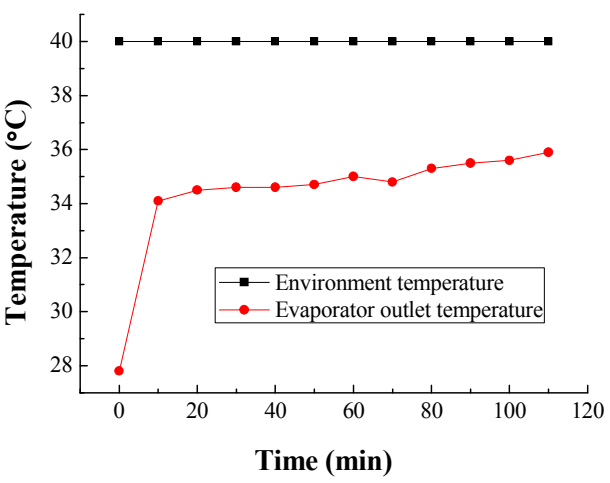

Fig.9 $40^{\circ} \mathrm{C}$

As shown in Fig. 8-11, air outlet temperature of evaporator increases gradually with the operation of heat pump. Surrounding temperature is constant, then temperature difference in evaporator decreases, which leads to bad performance of heat transfer and decrease of heat output. As shown in Fig. 6 and Fig. 7, the final temperature difference in evaporator is less than $1{ }^{\circ} \mathrm{C}$, when heat pump has not ability to produce heat. As shown in Fig. 8 and Fig. 9, the final temperature difference in evaporator can reach $3^{\circ} \mathrm{C}$ and $4^{\circ} \mathrm{C}$. The higher of surrounding temperature, the better performance of heat pump. Therefore, air source heat pump should not be fixed in the situation with low temperature.

On the case of ambient temperature of $10^{\circ} \mathrm{C}, 20^{\circ} \mathrm{C}, 30^{\circ} \mathrm{C}, 40^{\circ} \mathrm{C}$, compressor outlet pressure changes over time as shown in Figure 10-13.

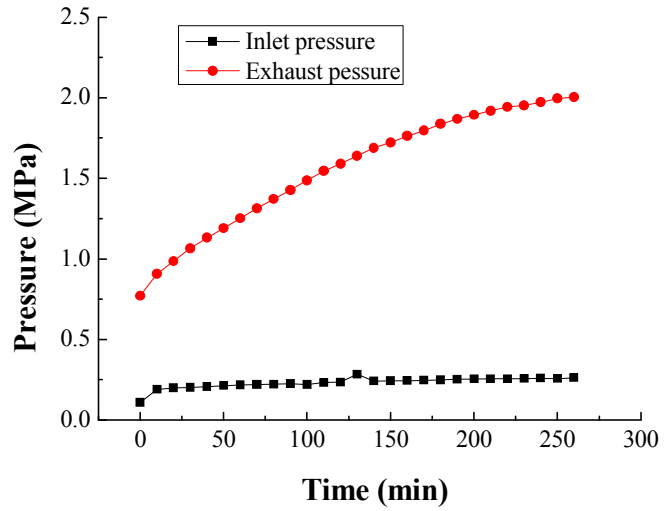

Fig. $1010^{\circ} \mathrm{C}$

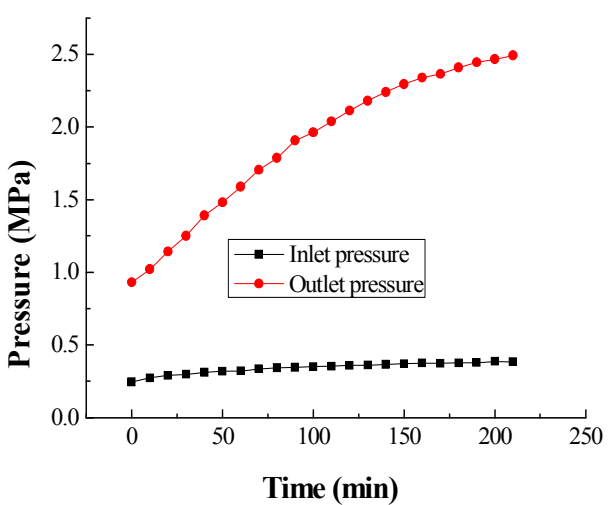

Fig. $1120^{\circ} \mathrm{C}$ 


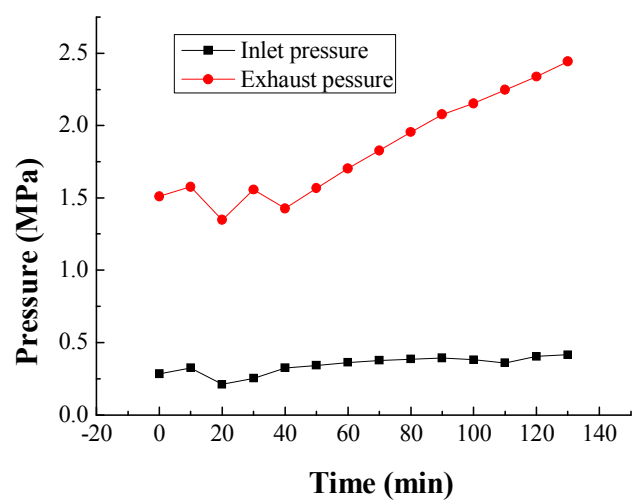

Fig. $1230^{\circ} \mathrm{C}$

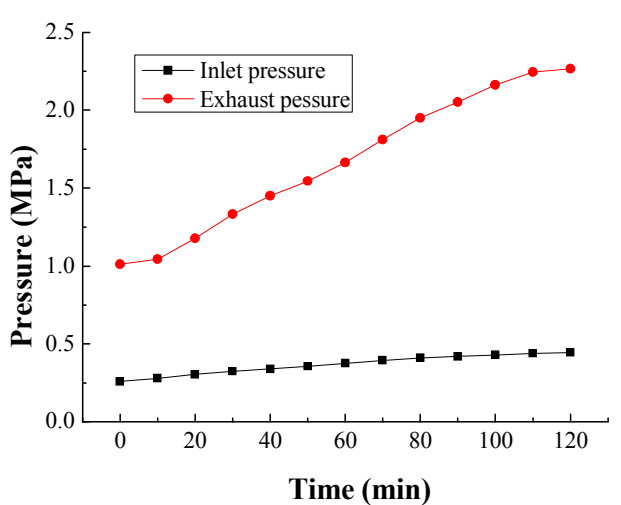

Fig. $1340^{\circ} \mathrm{C}$

As shown in Fig. 10-13, because surrounding temperature is constant, compressor inlet pressure varies slightly. Compressor outlet pressure increases obviously because of the increase of tank temperature. As shown in Fig. 10, compressor outlet pressure can reach $2.0 \mathrm{MPa}$ with surrounding temperature is $10^{\circ} \mathrm{C}$, while compressor outlet pressure can reach $2.5 \mathrm{MPa}$ which is compressor limit pressure with surrounding temperature higher than $20^{\circ} \mathrm{C}$. Therefore, heat pump already reaches its highest ability of heat production.

\section{Conclusions}

Air source heat pump apparatus were set up and the experiment was operated during $10^{\circ} \mathbf{C}, 20^{\circ} \mathbf{C}$, $30^{\circ} \mathrm{C}$ and $40^{\circ} \mathbf{C}$. Performance of air source heat pump are studied by experiment, and variation laws of exhaust temperature, evaporator outlet temperature and outlet presser of compressor were analyzed.

The results were as follows:

(1)Exhaust temperature of compressor increases gradually with the increase of tank temperature, but the temperature difference between exhaust temperature of compressor and tank temperature becomes little;

(2)Temperature difference in evaporator decreases, which leads to bad performance of heat transfer and decrease of heat output.

(3)Compressor outlet pressure increases obviously because of the increase of tank temperature.

\section{Acknowledgements}

This work was financially supported by Funding Project for Academic Human Resources Development in Institutions of Higher Learning Under the Jurisdiction of Beijing Municipality (No.PHR201007127).

\section{References}

[1] Weiguo Li, Xianmin Guo, Tao Sun. Journal of Refrigeration, Vol. 32(2011), p. 25-29

[2] Jibo Hao, Zhihua Wang, Yuguang Jiang, et al. Refrigeration and air-conditioning. Vol. 13(2013), p.59-62

[3] Junliang Zhang, Jingyi Wu, Ruzhu Wang. Journal of Shanghai jiaotong university, Vol. 40 (2006), p.1307-1311

[4] J Zhang, R Z Wang, J Y Wu. Applied thermal engineering, Vol. 27(2007), p.1029-1035

[5] Junjie Guo, Jingyi Wu, Ruzhu Wang., et al. Acta energiae solaris sinica, Vol. 28(2007), p. $1017-1020$

[6] Zhenhao Chen, Jingyi Wu, Ping Lu, et al. Energy technology, Vol. 26(2005), p. 117-119 
Energy and Power Technology

10.4028/www.scientific.net/AMR.805-806

Experiment Study on Performance of Air Source Heat Pump

10.4028/www.scientific.net/AMR.805-806.645 